\title{
Effect of extraction process and storage time on the quality attributes of pomegranate juice of two
}

\section{local pomegranate varieties}

\author{
Amal N. Alkuraieef, Amani AlJahani* \\ Department of Physical Sport Science, College of Education, Princess Nourah bint Abdulrahman University, Riyadh, \\ Saudi Arabia
}

*Corresponding Author: Amani Al-Juhani, Department of Physical Sport Science, College of Education, Princess Nourah bint Abdulrahman University, P.O. Box 84428, Riyadh 11671, Saudi Arabia. Email: ahaljahani@pnu.edu.sa

Received: 8 November 2021; Accepted: 30 December 2021; Published: 28 January 2022

(C) 2022 Codon Publications

OPEN ACCESS (c) (i) (우요

PAPER

\begin{abstract}
This study investigates the impact of two extraction processes (squeezing the whole fruit and centrifuging the seeds) of pomegranate juice and storage on sweet and sour pomegranate quality attributes. The $\mathrm{pH}$, acidity, and levels of organic acids, sugars and anthocyanin differed in both varieties and changed during the storage period. Fructose and glucose were the primary sugars, and citric acid was the dominant organic acid in the juice of both cultivars. A high level of established anthocyanin content was 15.40, 18.53, 18.03, 16.92, 16,68 and $15.47 \mathrm{mg} / \mathrm{L}$ when the storage period was $0,5,15,32,48$ and $72 \mathrm{~h}$, respectively, in the juice of sweet fruits obtained by squeezing the whole fruit. The juice prepared from the sweet fruits by squeezing method outscored, in all sensory quality attributes, the juice prepared by centrifuging process.
\end{abstract}

Keywords: anthocyanin; centrifugation of seeds; organic acids; sensory attributes; squeezing whole fruit

\section{Introduction}

Pomegranate (Punica granatum) fruit is known as 'miracle fruit' because of its vast food and pharmaceutical applications. The seeds are wrapped with juicy edible pulp and are consumed as food, pressed for juice production, and used as functional foods (Coronado-Reyes et al., 2021; Hegazi et al., 2021). Pomegranate fruit, peel, seeds and juice have high medicinal applications for treating and preventing various diseases such as inflammation, diabetes, diarrhea, obesity, dysentery, dental plaque and malaria (Ismail et al., 2012). In addition, parts of pomegranate fruit are also used as food additives, functional food materials and active ingredients in nutraceutical products (Akhtar et al., 2015). Pomegranate juice is a primary commercial product of pomegranate fruit with high consumer preferences because of its comprehensive nutritional and phytochemical components. It contains substantial amount of dietary polyphenols, tannins, anthocyanins and flavonoids with high potential antioxidant activities (Fahmy et al., 2020). Topalović et al. (2021) identified among 97 phenolic compounds, 23 anthocyanins and their derivatives, 33 ellagitannins and derivatives of ellagic acid, 12 flavonols, 4 flavonol glycosides, 1 flavone, 17 hydroxybenzoic acids and 7 hydroxycinnamic acids and their derivatives. Cyanidin-3,5-diglucoside and cyanidin-3-glucoside are reported as primary anthocyanins in pomegranates (Kostka et al., 2020). In addition, it was found that juice is a rich source of flavan-3-ols $(2,650-9,820 \mathrm{mg} / \mathrm{L})$, ellagitannins $(2,010-6,420 \mathrm{mg} / \mathrm{L})$ and hydroxybenzoic acids (720-3,390 mg/L) (Topalović et al., 2021).

Therefore, pomegranate juice is favored as a healthy juice with great applications for treating and preventing obesity, diabetes, blood pressure and inflammation (Hegazi et al., 2021). Factors such as cultivars, maturity stage, harvest season, climatic and agronomical conditions, post-harvest processing and juice extraction processes greatly affect the nutritional and phytochemical composition of pomegranate juice (Hegazi et al., 2021; Mphahlele et al., 2014). 
Optimization of these conditions is highly important to produce pomegranate juice with good quality attributes. Juice extraction is one of the critical steps that affect its functional properties, and this step is influenced by fruit genotype and other factors (Hegazi et al., 2021; Mena et al., 2014).

Generally, optimal time for fruit harvest and preparation process is the factor that plays an important role in the taste acceptability of consumers. In addition, the composition of organic acids and sugars in fruit juice plays a key role in flavor and sensory characteristics, such as $\mathrm{pH}$, total acidity and sweetness (Ikegaya et al., 2019). To date, several extraction processes have been used such as pressing the whole fruit or fruit halves by hand presser or squeezer, peeling off the fruit and extraction of juice using pressing and centrifugation, crushing the seeds and arils using the juice blender, and quartered cut fruit and pressing using rack and cloth (Hegazi et al., 2021). Of these processes, the hand pressing of fruit halves gave the highest yield of phenolic contents, anthocyanins and antioxidant activity (Mphahlele et al., 2016). Crushing the whole fruit or fruit halves resulted in a bitter taste because of the extraction of more tannins in the juice (Miguel et al., 2004). In addition to the extraction process, fruit type (sweet, sweet-sour and sour) affected pomegranate juice's nutritional and sensory quality attributes (Hegazi et al., 2021; Mphahlele et al., 2014).

In Saudi Arabia, great interest has been found in recent years in producing and consuming pomegranate juice.

Consequently, cultivation of pomegranate has increased greatly, and several genotypes are cultivated throughout the country. Sweet (Taifi) and sour (Bidah) genotypes are the primary pomegranate cultivars produced in western and southern Saudi Arabia. Today, studies on production of juice from these cultivars are scarce. Therefore, the present study was conducted to investigate the effect of juice extraction process (squeezing or centrifugation) and storage period (up to 3 days) on the quality attributes of pomegranate juice of Taifi and Bidah cultivars.

\section{Material and Methods}

\section{Materials}

The samples of sweet and sour pomegranate fruits were obtained from two different locations in Saudi Arabia. Sweet pomegranate fruits were obtained from a farm of Taif city located in western Saudi Arabia whereas sour fruits were obtained from Bidah village of southern Saudi Arabia. The samples were transferred to laboratory on the same day of harvesting under controlled conditions. After sorting of samples by removing damaged fruits and selecting the same size and maturity stage fruits, they were washed thoroughly with tap water and rinsed thrice in distilled water before extraction of juice by the two processes.

\section{Extraction of pomegranate juice}

The two processes used for the extraction of pomegranate juice from both sweet and sour fruits were as follows:

1. Peels of the fruits (10 fruits of each type) were removed manually, and the seeds were separated. The juice was extracted from the seeds using an electric centrifuge (Philips Electric HR2738/01 Citrus Press Juicer, France).

2. The fruits (10 fruits of each type) were cut with knives into two halves and squeezed using juice maker (Philips Viva Collection Juicer-HR1863, France) to obtain the juice.

The extraction processes were repeated for six times, and the resulting juice was transferred into sterilized bottles and stored in the dark at $4^{\circ} \mathrm{C}$ for $72 \mathrm{~h}$. The samples were collected at intervals of $0,5,15,32,48$ and $72 \mathrm{~h}$ for analyzing physicochemical properties.

\section{Determination of acidity and $\mathrm{pH}$}

The acidity was measured by titrating $10-\mathrm{mL}$ juice against $0.1-\mathrm{N} \mathrm{NaOH}$, and the results were expressed as percentage of citric acid (Association of Official Analytical Chemists [AOAC], 2000). The $\mathrm{pH}$ was measured using digital $\mathrm{pH}$ meter.

\section{Determination of organic acids}

Organic acids (tartaric, citric, malic and oxalic acids) of pomegranate juice samples were analyzed using the Highperformance liquid chromatography (HPLC) method as described in the AOAC (2000) standard methods with some modifications. Briefly, 10-g juice sample was centrifuged at 6,000 relative centrifugal force (RCF) for 20 min, and the supernatant was collected and filtered using $0.45-\mu \mathrm{m}$ filters (Millipore). Then, $20-\mu \mathrm{L}$ supernatant was injected into reverse phase $(\mathrm{RP})$ column $(250 \times 4.6 \mathrm{~mm})$ and processed using 50-mM potassium phosphate buffer and $70 \%$ methanol at a flow rate of $1 \mathrm{~mL} / \mathrm{min}$. The peaks were detected at $210 \mathrm{~nm}$, identified and quantified by comparing their retention time with the authentic standards of tartaric, citric, malic and oxalic acids.

\section{Determination of sugars}

The sugar contents of pomegranate juice were analyzed using the Shimadzu HPLC system (LC-10ADVP, Shimadzu, 
Kyoto, Japan) equipped with a Spherisorb $5 \mathrm{NH} 2$ column $(30 \times 0.65 \mathrm{~cm})$ and a 1530 refractive index detector (RID) (Shimadzu). Before analysis, 1-mL juice sample was centrifuged at 13,000 rpm for $20 \mathrm{~min}$. The supernatant was collected and filtered using $0.45-\mu \mathrm{m}$ Millipore filters. Then, $10-\mu \mathrm{L}$ sample was injected into the column having a temperature of $35^{\circ} \mathrm{C}$ and separated using $75 \%$ acetonitrile as mobile phase at a flow rate of $1 \mathrm{~mL} / \mathrm{min}$. The sugars were identified by comparing their retention time with authentic standards run under the same conditions, and the concentration was calculated using the standard curves of sugars.

\section{Determination of anthocyanin contents}

The anthocyanin contents of pomegranate juice samples were determined using the HPLC system described in the AOAC (2000) standard method. Briefly, 1-mL juice sample was centrifuged (3,000 RCF, $20 \mathrm{~min}$ ), and the supernatant was filtered using $0.45-\mu \mathrm{m}$ Millipore filters. The filtrate $(20 \mu \mathrm{L})$ was injected into a 100-RP 10 LiChroCart $^{\circ}$ column and separated using a linear gradient of $5 \%$ formic acid (A) and methanol from 15\% to 35\% (B) for 15 $\mathrm{min}$, followed isocratic application to a total run time of $20 \mathrm{~min}$. The flow rate was $1 \mathrm{~mL} / \mathrm{min}$, and the anthocyanin peaks were detected at $510 \mathrm{~nm}$. The anthocyanin content of the samples was detected by comparing their retention time with that of authentic standard anthocyanins quantified from the standard curves generated using 0-, 0.01-, 0.02-, 0.04- and 0.08-mg/L of authentic standard.

\section{Sensory analysis}

The sensory analysis of pomegranate juice samples of sweet and sour fruits extracted by above-mentioned two processes was conducted using 20-point scaling method (0-4: unacceptable, 5-8: acceptable, 9-12: good, 13-16: very good and 17-20: excellent; Chen et al., 1991). A panel comprising 30 trained staff of the College of Home Economics, Princess Nourahbint Abdulrahman University, Saudi Arabia, evaluated the color, smell, taste, texture and overall acceptance of pomegranate juice samples. The data were collected and subjected to statistical analysis.

\section{Statistical analysis}

The data of three experiments were collected and analyzed using One-Way Analysis of Variance (ANOVA). The mean was calculated using Student's $t$-test, and $p<0.05$ was considered as statistically significant (Roscoe, 1975).

\section{Results and Discussion}

\section{Effect of storage and extraction process on the $\mathrm{pH}$ and acidity of pomegranate juice}

The $\mathrm{pH}$ and acidity values of pomegranate juice of sweet and sour varieties as affected by extraction processes and storage period are shown in Table 1.

Table 1. Effect of storage and juice production method on the pH and acidity of local sweet (Taif) and sour (Bidah) pomegranate juice.

\begin{tabular}{|c|c|c|c|c|c|c|}
\hline \multirow[b]{2}{*}{ Parameters } & \multicolumn{6}{|c|}{ Storage (hours) } \\
\hline & 0 & 5 & 15 & 32 & 48 & 72 \\
\hline \multicolumn{7}{|l|}{ pH } \\
\hline $\begin{array}{l}\text { Squeezing sweet } \\
\text { pomegranate fruit }\end{array}$ & $4.26 \pm 0.03^{\mathrm{a}, \mathrm{A}}$ & $4.20 \pm 0.02^{\mathrm{a}, \mathrm{A}}$ & $4.26 \pm 0.02^{\mathrm{a}, \mathrm{A}}$ & $4.20 \pm 0.05^{\mathrm{a}, \mathrm{A}}$ & $4.12 \pm 0.08^{\mathrm{a}, \mathrm{B}}$ & $3.87 \pm 0.04^{\mathrm{a}, \mathrm{C}}$ \\
\hline $\begin{array}{l}\text { Centrifuging sweet } \\
\text { pomegranate seeds }\end{array}$ & $3.90 \pm 0.01^{\mathrm{b}, \mathrm{A}}$ & $4.01 \pm 0.09^{b, A}$ & $3.96 \pm 0.09^{b, A}$ & $3.87 \pm 0.10^{b, A}$ & $3.05 \pm 0.15^{b, c}$ & $3.63 \pm 0.20^{b, B}$ \\
\hline $\begin{array}{l}\text { Squeezing sour } \\
\text { pomegranate fruit }\end{array}$ & $3.80 \pm 0.03^{\mathrm{c}, \mathrm{A}}$ & $3.84 \pm 0.03^{\mathrm{c}, \mathrm{A}}$ & $3.86 \pm 0.09^{b, A}$ & $3.88 \pm 0.08^{b, A}$ & $3.60 \pm 0.15^{\mathrm{b}, \mathrm{B}}$ & $3.68 \pm 0.11^{\mathrm{c}, \mathrm{B}}$ \\
\hline $\begin{array}{l}\text { Centrifuging sour } \\
\text { pomegranate seeds }\end{array}$ & $3.60 \pm 0.06^{\mathrm{d}, \mathrm{A}}$ & $3.66 \pm 0.05^{\mathrm{d}, \mathrm{A}}$ & $3.60 \pm 0.05^{\mathrm{c}, \mathrm{A}}$ & $3.67 \pm 0.029^{c, A}$ & $3.44 \pm 0.05^{\mathrm{b}, \mathrm{B}}$ & $3.50 \pm 0.07^{\mathrm{c}, \mathrm{B}}$ \\
\hline \multicolumn{7}{|c|}{ Total acidity (mg/100 mL) } \\
\hline $\begin{array}{l}\text { Squeezing sweet } \\
\text { pomegranate fruit }\end{array}$ & $288.1 \pm 5.98^{c, B}$ & $289.8 \pm 7.78^{c, B}$ & $302.1 \pm 5.97^{\mathrm{c}, \mathrm{A}}$ & $296.0 \pm 3.50^{c, A, B}$ & $294.2 \pm 0.00^{\mathrm{d}, \mathrm{A}, \mathrm{B}}$ & $294.2 \pm 0.00^{\mathrm{d}, \mathrm{A}, \mathrm{B}}$ \\
\hline $\begin{array}{l}\text { Centrifuging sweet } \\
\text { pomegranate seeds }\end{array}$ & $394.1 \pm 29.21^{\mathrm{b}, \mathrm{A}}$ & $381.8 \pm 36.41^{\mathrm{b}, \mathrm{A}}$ & $404.6 \pm 26.42^{\mathrm{b}, \mathrm{A}}$ & $385.3 \pm 0.00^{b, A}$ & $385.3 \pm 0.00^{c, A}$ & $378.3 \pm 9.89^{\mathrm{c}, \mathrm{A}}$ \\
\hline $\begin{array}{l}\text { Squeezing sour } \\
\text { pomegranate fruit }\end{array}$ & $394.1 \pm 29.21^{b, B, C}$ & $381.8 \pm 36.41^{\mathrm{b}, \mathrm{B}, \mathrm{C}}$ & $404.6 \pm 26.42^{\mathrm{b}, \mathrm{A}, \mathrm{B}, \mathrm{C}}$ & $448.3 \pm 55.29^{\mathrm{a}, \mathrm{A}, \mathrm{B}}$ & $453.6 \pm 8.80^{\mathrm{b}, \mathrm{A}}$ & $444.3 \pm 4.04^{\mathrm{b}, \mathrm{A}, \mathrm{B}}$ \\
\hline $\begin{array}{l}\text { Centrifuging sour } \\
\text { pomegranate seeds }\end{array}$ & $449.2 \pm 16.26^{\mathrm{a}, \mathrm{A}}$ & $453.6 \pm 23.99^{\mathrm{a}, \mathrm{A}}$ & $452.7 \pm 24.81^{\mathrm{a}, \mathrm{A}}$ & $458.8 \pm 4.041^{\mathrm{a}, \mathrm{A}}$ & $462.3 \pm 5.7^{\mathrm{a}, \mathrm{A}}$ & $462.3 \pm 13.78^{\mathrm{a}, \mathrm{A}}$ \\
\hline
\end{tabular}

Means \pm SD of 10 samples followed by different superscript letters are significantly different at $p<0.05$. The small letters indicate differences in the treatments (columns), while the capital letter indicate differences in the storage time (rows). 
Comparing the pomegranate types demonstrated that sweet pomegranate juice had a higher $\mathrm{pH}$ than that of sour juice. Similarly, a previous report indicated that sweet pomegranate varieties have higher $\mathrm{pH}$ values than sour varieties (Fadavi et al., 2005). The $\mathrm{pH}$ of juice was significantly affected by the extraction process and pomegranate variety, and high $\mathrm{pH}$ was determined in the juice prepared by squeezed method of sweet fruit seeds, followed by that of centrifuged sweet fruit seeds, whereas the least $\mathrm{pH}$ was found in the juice prepared from the centrifuged sour fruit seeds $(p<0.05)$. The storage period of up to $32 \mathrm{~h}$ did not affect the $\mathrm{pH}$ of juice; however, as the storage period increased to $48 \mathrm{~h}$ and $72 \mathrm{~h}$, the $\mathrm{pH}$ of both types of pomegranate juice was decreased. The change in $\mathrm{pH}$ during extended storage period of pomegranate fruit juice was likely due to the formation of acids because of enzymatic and microbial activities during storage. The acidity was also higher $(p$ $<0.05$ ) in juice prepared from sour pomegranate fruits than that of sweet fruits, which agreed with the previous report of the juice prepared from 10 pomegranate varieties (Fadavi et al., 2005). The highest acidity and the lowest $\mathrm{pH}$ of pomegranate juice of sour fruit types could be due to high acid content of sour varieties (Fadavi et al., 2005). In this study, the extraction process greatly influenced the acidity of juice, with the highest values being found in the juice prepared from centrifuged sour fruit seeds, followed by that of squeezed sour fruit seeds, whereas the least acidity was observed in juice prepared from squeezed sweet fruits. Again, the storage did not affect the acidity of the juice extracted by both processes of pomegranate fruits. It has been reported that the acidity of pomegranate juice obtained by centrifuging the seeds decreased after $32 \mathrm{~h}$ of storage whereas decrease in acidity of the juice obtained by squeezing method was less noticeable (Miguel et al., 2004). Difference between the results of these studies could be due to variation in the genetic background of used pomegranate fruits.

\section{Effect of storage and extraction process on the content of organic acids of pomegranate juice}

The content of organic acids in the pomegranate juice prepared from two types of fruits and extraction processes during $72 \mathrm{~h}$ of storage at $4^{\circ} \mathrm{C}$ is presented in Table 2. Both fruit types (sweet and sour) and extraction processes (squeezing the fruit or centrifuging the seeds) affected the content of organic acids in different manners $(p<$ 0.05 ) whereas the effect of storage period on content of organic acids was limited. Citric acid is the major organic acid in pomegranate juice. Its level was higher in the juice prepared from sour fruits than that prepared from sweet variety regardless of the extraction method, suggesting that the fruit type influenced the content of citric acid found in pomegranate juice $(p<0.05)$. Similarly, citric acid was the primary organic acid found in the juice of various pomegranate varieties, and its content was affected by these varieties as reported by other studies (Aarabi $e t$ al., 2008; Türkyllmaz, 2013). Moreover, citric acid was found higher in sour cultivars than sweet ones (GhaderiGhahfarokhi et al., 2016). The citric acid content in sour fruit juice remained unchanged for $72 \mathrm{~h}$ of storage, while it was reduced to minimum values at $15 \mathrm{~h}$ of storage in sweet fruit juice but increased again with the progress of storage period $(p<0.05)$. Changes in citric acid during 60 days of storage differed due to variation in the fruit type, chemical changes and extraction processes used, as reported previously for various pomegranate cultivars (Aarabi et al., 2008). Tartaric acid and malic acid are the second major organic acids found in pomegranate juice of different varieties, as reported by previous studies (Aarabi et al., 2008). Content of tartaric acid was affected more by the extraction process than the fruit type. The highest values were observed in the juice prepared by squeezing of sweet and sour fruits $(p<0.05)$. The increased tartaric acid in the juice obtained by squeezing the whole fruits could be due to the fact that some amount of acid is found in the peels of the fruit and peeling off could lead to releasing of this amount. The storage period did not affect the tartaric acid content found in both types of pomegranate juices.

The fruit type and the extraction process also affected the content of malic acid in pomegranate juice, and a pronounced effect was observed in sour fruit juice. The highest level of malic acid was found in the juice prepared by squeezing the whole sour fruits, while the least value was found in the juice prepared from the centrifugation of sour pomegranate fruit seeds $(p<0.05)$. Variation in the content of malic acid was reported in the juice prepared from different pomegranate cultivars, suggesting the influence of cultivar on malic acid (Aarabi et al., 2008; Gundogdu and Yilmaz, 2012; Türkyllmaz, 2013). Malic acid levels were gradually reduced with the storage time of the juice prepared by centrifuging the seeds of sour fruits. Decrease in malic acid during storage was likely due to its metabolism by indigenous microflora present in the juice. Decrease in the content of organic acids after pressing step was observed in pomegranate juice (Akyıldız et al., 2020).

The level of oxalic acid also varied between fruit types and extraction processes of the juice, with the highest value found in the juice prepared by squeezing whole sweet pomegranate fruits, and the lowest value found in the juice prepared by centrifugation of sour fruit seeds $(p<0.05)$. Similarly, different levels of oxalic acid were reported in pomegranate juice obtained from different cultivars and by various extraction processes (Aarabi et al., 2008; Gundogdu and Yilmaz, 2012; Türkyılmaz, 
Table 2. Effect of storage and juice production method on the organic acids of local sweet (Taif) and sour (Bidah) pomegranate juice.

\begin{tabular}{|c|c|c|c|c|c|c|}
\hline \multirow[b]{2}{*}{ Parameters } & \multicolumn{6}{|c|}{ Storage (hours) } \\
\hline & 0 & 5 & 15 & 32 & 48 & 72 \\
\hline \multicolumn{7}{|l|}{ Citric acid (mg/100 mL) } \\
\hline $\begin{array}{l}\text { Squeezing sweet } \\
\text { pomegranate fruit }\end{array}$ & $357.88 \pm 65.76^{b, A, B}$ & $354.14 \pm 11.15^{\mathrm{b}, \mathrm{B}}$ & $261.73 \pm 9.98^{b, c}$ & $367.57 \pm 4.66^{b, A, B}$ & $374.17 \pm 9.67^{b, A}$ & $379.32 \pm 7.12^{\mathrm{b}, \mathrm{A}}$ \\
\hline $\begin{array}{l}\text { Centrifuging sweet } \\
\text { pomegranate seeds }\end{array}$ & $344.63 \pm 6.40^{\mathrm{b}, \mathrm{B}}$ & $435.10 \pm 45.87^{\mathrm{b}, \mathrm{A}}$ & $292.87 \pm 57.08^{b, c}$ & $369.49 \pm 15.17^{\mathrm{b}, \mathrm{B}}$ & $373.21 \pm 20.83^{\mathrm{b}, \mathrm{B}}$ & $374.31 \pm 25.82^{\mathrm{b}, \mathrm{B}}$ \\
\hline $\begin{array}{l}\text { Squeezing sour } \\
\text { pomegranate fruit }\end{array}$ & $471.13 \pm 51.66^{\mathrm{a}, \mathrm{A}}$ & $476.84 \pm 2.27^{\mathrm{a}, \mathrm{A}}$ & $474.53 \pm 3.43^{\mathrm{a}, \mathrm{A}}$ & $481.34 \pm 4.92^{\mathrm{a}, \mathrm{A}}$ & $487.07 \pm 1.363^{\mathrm{a}, \mathrm{A}}$ & $484.98 \pm 6.04^{\mathrm{a}, \mathrm{A}}$ \\
\hline $\begin{array}{l}\text { Centrifuging sour } \\
\text { pomegranate seeds }\end{array}$ & $469.36 \pm 1.81^{\mathrm{a}, \mathrm{A}}$ & $472.48 \pm 1.45^{\mathrm{a}, \mathrm{A}}$ & $477.14 \pm 9.39^{\mathrm{a}, \mathrm{A}}$ & $479.58 \pm 7.73^{\mathrm{a}, \mathrm{A}}$ & $479.48 \pm 3.62^{\mathrm{a}, \mathrm{A}}$ & $476.98 \pm 1.40^{\mathrm{a}, \mathrm{A}}$ \\
\hline \multicolumn{7}{|c|}{ Tartaric acid (mg/100 mL) } \\
\hline $\begin{array}{l}\text { Squeezing sweet } \\
\text { pomegranate fruit }\end{array}$ & $159.30 \pm 6.69^{\mathrm{a}, \mathrm{A}}$ & $185.98 \pm 6.86^{\mathrm{a}, \mathrm{A}}$ & $156.99 \pm 7.38^{\mathrm{a}, \mathrm{A}}$ & $155.11 \pm 8.04^{\mathrm{a}, \mathrm{A}}$ & $155.05 \pm 7.13^{\mathrm{a}, \mathrm{A}}$ & $154.15 \pm 7.42^{\mathrm{a}, \mathrm{A}}$ \\
\hline $\begin{array}{l}\text { Centrifuging sweet } \\
\text { pomegranate seeds }\end{array}$ & $135.64 \pm 6.12^{\mathrm{b}, \mathrm{A}}$ & $134.76 \pm 5.67^{\mathrm{b}, \mathrm{A}}$ & $133.34 \pm 6.09^{\mathrm{b}, \mathrm{A}}$ & $131.93 \pm 6.2^{\mathrm{b}, \mathrm{A}}$ & $131.31 \pm 6.02^{\mathrm{b}, \mathrm{A}}$ & $129.62 \pm 6.46^{\mathrm{b} . \mathrm{A}}$ \\
\hline $\begin{array}{l}\text { Squeezing sour } \\
\text { pomegranate fruit }\end{array}$ & $157.30 \pm 0.38^{\mathrm{a}, \mathrm{A}}$ & $158.79 \pm 13.61^{\mathrm{a}, \mathrm{A}}$ & $158.81 \pm 13.58^{\mathrm{a}, \mathrm{A}}$ & $152.28 \pm 4.47^{\mathrm{a}, \mathrm{A}}$ & $147.24 \pm 0.147^{\mathrm{a}, \mathrm{B}}$ & $155.32 \pm 10.03^{\mathrm{a}, \mathrm{A}}$ \\
\hline $\begin{array}{l}\text { Centrifuging sour } \\
\text { pomegranate seeds }\end{array}$ & $133.91 \pm .0 .17^{\mathrm{b}, \mathrm{A}}$ & $135.16 \pm 0.12^{\mathrm{b}, \mathrm{B}}$ & $134.87 \pm 0.45^{\mathrm{b}, \mathrm{B}}$ & $125.05 \pm 0.28^{b, c}$ & $124.66 \pm 0.26^{\mathrm{b}, \mathrm{c}}$ & $123.10 \pm .0 .91^{\mathrm{b}, \mathrm{D}}$ \\
\hline \multicolumn{7}{|l|}{ Malic acid (mg/100 mL) } \\
\hline $\begin{array}{l}\text { Squeezing sweet } \\
\text { pomegranate fruit }\end{array}$ & $116.38 \pm 2.16^{\mathrm{b}, \mathrm{A}}$ & $116.59 \pm 5.29^{\mathrm{a}, \mathrm{A}}$ & $108.66 \pm 11.56^{\mathrm{b}, \mathrm{A}}$ & $109.34 \pm 8.69^{\mathrm{a}, \mathrm{A}}$ & $104.81 \pm 7.87^{\mathrm{a}, \mathrm{b}, \mathrm{A}}$ & $104.75 \pm 7.05^{\mathrm{b}, \mathrm{A}}$ \\
\hline $\begin{array}{l}\text { Centrifuging sweet } \\
\text { pomegranate seeds }\end{array}$ & $104.86 \pm 10.54^{\mathrm{b}, \mathrm{A}}$ & $102.35 \pm 11.39^{\mathrm{b}, \mathrm{A}}$ & $100.22 \pm 10.95^{\mathrm{b}, \mathrm{A}}$ & $97.11 \pm 11.30^{\mathrm{b}, \mathrm{A}}$ & $97.42 \pm 9.95^{b, A}$ & $95.28 \pm 11.58^{\mathrm{c}, \mathrm{A}}$ \\
\hline $\begin{array}{l}\text { Squeezing sour } \\
\text { pomegranate fruit }\end{array}$ & $123.33 \pm 0.57^{\mathrm{a}, \mathrm{A}}$ & $122.66 \pm 1.54^{\mathrm{a}, \mathrm{A}}$ & $116.77 \pm 0.71^{\mathrm{a}, \mathrm{A}}$ & $112.61 \pm 0.56^{a, B}$ & $112.77 \pm 7.24^{\mathrm{a}, \mathrm{B}}$ & $123.44 \pm 9.12^{\mathrm{a}, \mathrm{A}}$ \\
\hline $\begin{array}{l}\text { Centrifuging sour } \\
\text { pomegranate seeds }\end{array}$ & $92.77 \pm 0.68^{\mathrm{c}, \mathrm{A}}$ & $87.87 \pm 0.46^{\mathrm{c}, \mathrm{B}}$ & $88.12 \pm 0.58^{\mathrm{c}, \mathrm{B}}$ & $85.67 \pm 0.64^{c, c}$ & $85.15 \pm 0.29 c, c$ & $85.44 \pm 0.81^{\mathrm{d}, \mathrm{C}}$ \\
\hline \multicolumn{7}{|l|}{ Oxalic acid (mg/100 mL) } \\
\hline $\begin{array}{l}\text { Squeezing sweet } \\
\text { pomegranate fruit }\end{array}$ & $20.62 \pm 2.61^{\mathrm{a}, \mathrm{A}}$ & $20.36 \pm 2.75^{\mathrm{a}, \mathrm{A}}$ & $18.61 \pm 2.78^{\mathrm{a}, \mathrm{A}}$ & $21.91 \pm 2.26^{\mathrm{a}, \mathrm{A}}$ & $19.97 \pm 2.25^{\mathrm{a}, \mathrm{A}}$ & $20.02 \pm 2.59^{\mathrm{a}, \mathrm{A}}$ \\
\hline $\begin{array}{l}\text { Centrifuging sweet } \\
\text { pomegranate seeds }\end{array}$ & $11.19 \pm 1.41^{\mathrm{b}, \mathrm{A}, \mathrm{B}}$ & $10.61 \pm 1.21^{\mathrm{b}, \mathrm{A}, \mathrm{B}}$ & $9.83 \pm 0.80^{\mathrm{b}, \mathrm{B}}$ & $12.06 \pm 1.25^{\mathrm{b}, \mathrm{A}}$ & $11.19 \pm 1.08^{\mathrm{b}, \mathrm{A}, \mathrm{B}}$ & $11.47 \pm 0.91^{\mathrm{b}, \mathrm{A}, \mathrm{B}}$ \\
\hline $\begin{array}{l}\text { Squeezing sour } \\
\text { pomegranate fruit }\end{array}$ & $11.73 \pm 0.42^{\mathrm{b}, \mathrm{A}, \mathrm{B}}$ & $11.30 \pm 0.20^{\mathrm{b}, \mathrm{A}, \mathrm{B}}$ & $10.90 \pm 0.86^{b, B, C}$ & $10.64 \pm 0.43^{b, c}$ & $10.41 \pm 0.59^{b, c}$ & $12.57 \pm 1.35^{\mathrm{b}, \mathrm{A}}$ \\
\hline $\begin{array}{l}\text { Centrifuging sour } \\
\text { pomegranate seeds }\end{array}$ & $4.33 \pm 1.54^{\mathrm{c}, \mathrm{C}}$ & $5.72 \pm 1.61^{\mathrm{C}, \mathrm{A}, \mathrm{B}}$ & $6.45 \pm 0.69^{c, A, B}$ & $6.37 \pm 0.61^{\mathrm{c}, \mathrm{A}, \mathrm{B}}$ & $5.80 \pm 0.45^{\mathrm{c}, \mathrm{B}, \mathrm{C}}$ & $8.15 \pm 0.54^{\mathrm{a}, \mathrm{A}}$ \\
\hline \multicolumn{7}{|c|}{ Total organic acids (mg/100 mL) } \\
\hline $\begin{array}{l}\text { Squeezing sweet } \\
\text { pomegranate fruit }\end{array}$ & $654.18 \pm 4.78^{\mathrm{c}, \mathrm{A}}$ & $650.07 \pm 10.81^{\mathrm{c}, \mathrm{A}}$ & $454.98 \pm 15.58^{c, B}$ & $653.92 \pm 4.11^{\mathrm{c}, \mathrm{A}}$ & $654.00 \pm 11.77^{\mathrm{c}, \mathrm{A}}$ & $658.24 \pm 6.6^{c, A}$ \\
\hline $\begin{array}{l}\text { Centrifuging sweet } \\
\text { pomegranate seeds }\end{array}$ & $596.32 \pm 59.53^{\mathrm{dA}}$ & $592.81 \pm 54.79^{\mathrm{dA}}$ & $536.25 \pm 65.42^{\mathrm{cA}}$ & $610.59 \pm 24.58^{\mathrm{dA}}$ & $613.13 \pm 29.28^{\mathrm{dA}}$ & $610.68 \pm 35.03^{\mathrm{dA}}$ \\
\hline $\begin{array}{l}\text { Squeezing sour } \\
\text { pomegranate fruit }\end{array}$ & $763.49 \pm 2.29^{\mathrm{aA}}$ & $769.60 \pm 11.60^{\mathrm{aA}}$ & $761.00 \pm 16.49^{\mathrm{aA}}$ & $756.87 \pm 3.74^{\mathrm{bA}}$ & $757.48 \pm 7.16^{\mathrm{aA}}$ & $776.30 \pm 12.47^{\mathrm{aA}}$ \\
\hline $\begin{array}{l}\text { Centrifuging sour } \\
\text { pomegranate seeds }\end{array}$ & $700.37 \pm 2.48^{\mathrm{bB}}$ & $701.23 \pm 0.69^{\mathrm{bB}}$ & $706.58 \pm 9.04^{\mathrm{bB}}$ & $969.68 \pm 7.62^{\mathrm{aA}}$ & $695.09 \pm 3.33^{\text {bB }}$ & $693.67 \pm 2.34^{\mathrm{bB}}$ \\
\hline
\end{tabular}

Means \pm SD of 10 samples followed by different superscript letters are significantly different at $p<0.05$. The small letters indicate differences in the treatments (columns), while the capital letters indicate differences in the storage time (rows).

2013). During cold storage, the oxalic acid content fluctuated except in the case of juice prepared from the whole sweet pomegranate fruits, which demonstrated no change during storage.
The highest total organic acids content was found in the juice prepared by squeezing the whole sour fruits whereas the lowest organic acids content was found in the juice obtained by centrifuging the seeds of sweet fruits. 
Similarly, a higher level of organic acids was reported in the juice obtained from sour pomegranate fruits than that obtained from sweet fruits (Ghaderi-Ghahfarokhi et al., 2016). Among the fruit types, the highest values of organic acids were found in the juice prepared from whole fruit, indicating that removal of peels reduced total organic acids. The content of total organic acids in pomegranate juice was not influenced by storage, except in the case of the juice prepared from whole sweet fruits, which demonstrated decrease at $15 \mathrm{~h}$ and then increased to the same level, and the juice prepared from sour fruit seeds, which increased to the maximum at $32 \mathrm{~h}$ and thereafter decreased to the initial level with progression in storage time $(p<0.05)$. The changes, i.e., increasing and decreasing trends, in the level of organic acids during storage were likely due to occurrence of different chemical and enzymatic reactions. Content of organic acids fluctuated during storage, indicating decrease in the first $15 \mathrm{~h}$ of storage followed by an increment with progress in storage time (Aarabi et al., 2008). Variations in the levels of organic acids in pomegranate juice of different varieties and prepared by various processes have been reported in numerous studies (Aarabi et al., 2008; Gundogdu and Yilmaz, 2012; Türkyılmaz, 2013). The differences in the level of organic acids of pomegranate juice among these studies were likely due to variations in the genetic makeup, growing region and conditions, season and maturity stage, cultural and post-harvest practices, processes of preparing juice, and analysis of organic acids.

\section{Effect of storage and extraction process on the content of sugars in pomegranate juice}

The content of sugars in pomegranate juice prepared from sweet and sour fruits using two extraction processes as affected by storage time is shown in Table 3 . Fructose and glucose were the primary sugars found in pomegranate juice, and content of both was affected by fruit type and extraction and processing processes. Previous studies have also indicated fructose and glucose as dominant carbohydrates in pomegranate juice (Aarabi et al., 2008; Fadavi et al., 2005; Hasnaoui et al., 2011). On 0 day of storage, the highest $(p<0.05)$ level of fructose was found in the juice prepared from seeds of sweet pomegranate fruit by centrifugation extraction, whereas the least value was observed in the juice prepared by squeezing whole sweet fruit, suggesting the influence of extraction method on the fructose content of juice. The fructose content in the juice was also affected $(p<0.05)$ by the storage time in a fluctuated manner, reaching the highest level at 15 $\mathrm{h}$ (juice from the seeds of sweet fruits), $32 \mathrm{~h}$ (juice from whole sour fruits) and $48 \mathrm{~h}$ (juice from whole sweet fruits and seeds of sour fruits). The increase in the content of fructose during storage could be due enzymatic hydrolysis of disaccharides and polysaccharides present in the juice. However, as the storage period extended to $72 \mathrm{~h}$, chemical complexing reactions and microbial metabolism might occur, which reduced the extractability of fructose and thereby its concentration.

The content of glucose was highest in the juice obtained by centrifugation of seeds of sweet fruits $(p<0.05)$. Storage greatly affected the glucose content of the juice of both types of fruits and extraction processes. Glucose content generally increased to the maximum at $15 \mathrm{~h}$ (juice obtained by centrifugation process of sweet fruit seeds) and $48 \mathrm{~h}$ (juice of whole sweet and sour fruits and the seeds of sour fruits). The fruit type and the extraction process did not affect the total sugar level on 0 day of storage. However, as the storage time progressed, significant changes were observed in juice depending on the fruit types and extraction processes, especially at $72 \mathrm{~h}$ of storage, suggesting the combined effects of fruit type, extraction process and extraction time on the total sugar contents of pomegranate juice. Previous reports have also indicated that sugar content in pomegranate juice decreased at $5 \mathrm{~h}$ of storage and then increased as the storage time progressed to the maximum at $48 \mathrm{~h}$, and reduced again by the end of storage period (Aarabi et al., 2008). This was attributed to decrease in carbohydrates because of the de novo synthesis of anthocyanin (Aarabi et al., 2008). This might be the same reason for changes in the content of sugars during storage of pomegranate juice in the present study.

\section{Effect of storage and extraction process on the anthocyanin content of pomegranate juice}

The anthocyanin content of pomegranate juice of two fruit types (sweet and sour) and two extraction processes (squeezing whole fruit and centrifuging of seeds) as affected by the storage time of the juice is shown in Table 4. The level of anthocyanin in pomegranate juice was affected by fruit type, extraction process and storage time $(p<0.05)$. The highest anthocyanin level was observed in the juice prepared from whole sweet fruits, followed by that from whole sour fruits. The least level of anthocyanin was found in the juice prepared by centrifuging of seeds of both fruit types. This could be attributed to the fact that anthocyanin is found in pomegranate fruit peels, and removing the peels reduced its content in the juice. Compared the fruit types, the highest anthocyanin content was observed in the juice prepared from whole sweet fruits than that from the whole sour ones. During storage, the anthocyanin content of the juice prepared from sweet fruits increased to the maximum at $5 \mathrm{~h}$ (whole fruit juice) and $15 \mathrm{~h}$ (seed juice). Although the anthocyanin content decreased with increase in storage time, it decreased concomitantly in the case of sour fruits with increase of storage time $(p<0.05)$. The increase in anthocyanin content 
Table 3. Effect of storage and juice production method on the sugar contents of local sweet (Taif) and sour (Bidah) pomegranate juice.

\begin{tabular}{|c|c|c|c|c|c|c|}
\hline \multirow[b]{2}{*}{ Parameters } & \multicolumn{6}{|c|}{ Storage (hours) } \\
\hline & 0 & 5 & 15 & 32 & 48 & 72 \\
\hline \multicolumn{7}{|l|}{ Fructose $(\mathrm{g} / 100 \mathrm{~mL})$} \\
\hline Squeezing sweet pomegranate fruit & $7.22 \pm 0.34^{c, c}$ & $7.56 \pm 0.58^{\mathrm{a}, \mathrm{B}}$ & $7.67 \pm 0.32^{\mathrm{b}, \mathrm{B}}$ & $6.57 \pm 1.44^{\mathrm{d}, \mathrm{D}}$ & $8.82 \pm 2.55^{\mathrm{a}, \mathrm{A}}$ & $7.65 \pm 0.34^{\mathrm{a}, \mathrm{b}, \mathrm{B}}$ \\
\hline Centrifuging sweet pomegranate seeds & $7.86 \pm 0.12^{\mathrm{a}, \mathrm{A}, \mathrm{B}}$ & $7.95 \pm 0.08^{\mathrm{a}, \mathrm{A}, \mathrm{B}}$ & $8.10 \pm 0.24^{\mathrm{a}, \mathrm{A}}$ & $7.73 \pm .010^{\mathrm{c}, \mathrm{B}, \mathrm{C}}$ & $7.50 \pm 0.39^{\mathrm{a}, \mathrm{c}}$ & $7.73 \pm 0.19^{\mathrm{a}, \mathrm{B}, \mathrm{C}}$ \\
\hline Squeezing sour pomegranate fruit & $7.71 \pm 0.01^{\mathrm{b}, \mathrm{A}}$ & $7.82 \pm 0.04^{\mathrm{a}, \mathrm{A}}$ & $7.94 \pm 0.04^{\mathrm{a}, \mathrm{b}, \mathrm{A}}$ & $8.05 \pm 0.03^{\mathrm{a}, \mathrm{A}}$ & $7.88 \pm 0.12^{\mathrm{a}, \mathrm{A}}$ & $6.98 \pm 0.81^{\mathrm{b}, \mathrm{B}}$ \\
\hline Centrifuging sour pomegranate seeds & $7.69 \pm 0.00^{\mathrm{b}, \mathrm{B}}$ & $7.68 \pm 0.02^{\mathrm{a}, \mathrm{B}}$ & $7.81 \pm 0.02^{\mathrm{a}, \mathrm{b}, \mathrm{A}, \mathrm{B}}$ & $7.84 \pm 0.03^{\mathrm{b}, \mathrm{A}, \mathrm{B}}$ & $7.89 \pm 0.04^{\mathrm{a}, \mathrm{A}}$ & $7.81 \pm 0.08^{\mathrm{a}, \mathrm{A}, \mathrm{B}}$ \\
\hline \multicolumn{7}{|l|}{ Glucose (g/100 mL) } \\
\hline Squeezing sweet pomegranate fruit & $6.93 \pm 0.21^{\mathrm{b}, \mathrm{A}, \mathrm{B}}$ & $7.12 \pm 0.45^{\mathrm{a}, \mathrm{b}, \mathrm{A}, \mathrm{B}}$ & $7.37 \pm 0.41^{\mathrm{b}, \mathrm{A}, \mathrm{B}}$ & $6.25 \pm 1.19^{\mathrm{d}, \mathrm{B}}$ & $8.66 \pm 2.45^{\mathrm{a}, \mathrm{A}}$ & $7.36 \pm 0 . .20^{\mathrm{a}, \mathrm{A}, \mathrm{B}}$ \\
\hline Centrifuging sweet pomegranate seeds & $7.45 \pm 0.17^{\mathrm{a}, \mathrm{B}}$ & $7.56 \pm 0.31^{\mathrm{a}, \mathrm{B}}$ & $7.98 \pm 0.03^{\mathrm{a}, \mathrm{A}}$ & $7.55 \pm 0.09^{a, B}$ & $7.47 \pm 0.29^{\mathrm{a}, \mathrm{B}}$ & $7.62 \pm 0.25^{\mathrm{a}, \mathrm{B}}$ \\
\hline Squeezing sour pomegranate fruit & $7.07 \pm 0.01^{b, c}$ & $7.16 \pm 0.03^{\mathrm{a}, \mathrm{b}, \mathrm{B}}$ & $7.32 \pm 0.01^{\mathrm{b}, \mathrm{A}}$ & $7.35 \pm 0.03^{b, A}$ & $7.38 \pm 0.05^{\mathrm{a}, \mathrm{A}}$ & $6.67 \pm 0.73^{b, D}$ \\
\hline Centrifuging sour pomegranate seeds & $6.89 \pm 0.01^{b, D}$ & $6.99 \pm 0.03^{b, c}$ & $7.13 \pm 0.03^{\mathrm{c}, \mathrm{B}}$ & $7.16 \pm 0.02^{\mathrm{c}, \mathrm{B}}$ & $7.26 \pm 0.03^{\mathrm{a}, \mathrm{A}}$ & $7.24 \pm 0.05^{\mathrm{a}, \mathrm{b}, \mathrm{A}}$ \\
\hline \multicolumn{7}{|l|}{ Total sugars (Brix) } \\
\hline Squeezing sweet pomegranate fruit & $16.0 \pm 0.00^{\mathrm{a}, \mathrm{c}}$ & $16.8 \pm 0.00^{\mathrm{b}, \mathrm{A}}$ & $16.5 \pm 0.00 \mathrm{~b}, \mathrm{~B}$ & $16.0 \pm 0.00^{c, c}$ & $15.0 \pm 0.00^{\mathrm{b}, \mathrm{D}}$ & $8.5 \pm 0.00 \mathrm{c}, \mathrm{E}$ \\
\hline Centrifuging sweet pomegranate seeds & $16.0 \pm 0.00^{\mathrm{a}, \mathrm{B}}$ & $17.3 \pm 0.50^{\mathrm{a}, \mathrm{A}}$ & $17.0 \pm 0.00^{\mathrm{a}, \mathrm{A}, \mathrm{B}}$ & $17.3 \pm 0.29^{\mathrm{a}, \mathrm{A}}$ & $16.5 \pm 0.58^{\mathrm{a}, \mathrm{A}, \mathrm{B}}$ & $17.3 \pm 0.50^{\mathrm{a}, \mathrm{A}}$ \\
\hline Squeezing sour pomegranate fruit & $16.0 \pm 0.00^{\mathrm{a}, \mathrm{B}}$ & $16.0 \pm 0.50^{\mathrm{b}, \mathrm{A}, \mathrm{B}}$ & $16.0 \pm 0.00^{\mathrm{b}, \mathrm{B}}$ & $16.5 \pm 0.00^{\mathrm{b}, \mathrm{A}}$ & $16.0 \pm 0.41^{\mathrm{a}, \mathrm{B}}$ & $9.3 \pm 1.50^{c, c}$ \\
\hline Centrifuging sour pomegranate seeds & $16.0 \pm 0.00^{\mathrm{a}, \mathrm{A}}$ & $16.0 \pm 0.00^{b, A}$ & $16.0 \pm 0.00^{b, A}$ & $16.6 \pm 0.25^{b, A}$ & $15.8 \pm 0.29^{b, B}$ & $13.1 \pm 0.85^{b, c}$ \\
\hline
\end{tabular}

Means \pm SD of 10 samples followed by different superscript letters are significantly different at $p<0.05$. The small letters indicate differences in the treatments (columns), while the capital letters indicate differences in the storage time (rows).

Table 4. Effect of storage and juice production method on the anthocyanin contents of local sweet (Taif) and sour (Bidah) pomegranate juice.

\begin{tabular}{|c|c|c|c|c|c|c|}
\hline \multirow[b]{2}{*}{ Parameters } & \multicolumn{6}{|c|}{ Storage (hours) } \\
\hline & 0 & 5 & 15 & 32 & 48 & 72 \\
\hline \multicolumn{7}{|l|}{ Alkali treatment } \\
\hline Squeezing sweet pomegranate fruit & $15.40 \pm 0.49^{a, c}$ & $18.53 \pm 0.43^{\mathrm{a}, \mathrm{A}}$ & $18.03 \pm 0.20^{\mathrm{a}, \mathrm{A}}$ & $16.92 \pm 0.44^{\mathrm{a}, \mathrm{B}}$ & $16.68 \pm 0.035^{\mathrm{a}, \mathrm{B}}$ & $15.47 \pm 6.86^{\mathrm{a}, \mathrm{c}}$ \\
\hline Centrifuging sweet pomegranate seeds & $11.07 \pm 1.65^{\mathrm{c}, \mathrm{C}}$ & $14.32 \pm 2.81^{\mathrm{b}, \mathrm{A}}$ & $14.92 \pm 0.07^{\mathrm{b}, \mathrm{A}}$ & $14.12 \pm 0.53^{b, A, B}$ & $13.55 \pm 0.68^{\mathrm{b}, \mathrm{B}}$ & $12.15 \pm 0.58^{\mathrm{a}, \mathrm{c}}$ \\
\hline Squeezing sour pomegranate fruit & $14.74 \pm 0.77^{\mathrm{b}, \mathrm{A}}$ & $12.79 \pm 0.09^{\mathrm{c}, \mathrm{B}}$ & $12.47 \pm 0.08^{\mathrm{c}, \mathrm{B}}$ & $11.99 \pm 0.11^{\mathrm{c}, \mathrm{c}}$ & $11.70 \pm 0.12^{\mathrm{C}, \mathrm{D}}$ & $11.11 \pm 0.36^{\mathrm{a}, \mathrm{E}}$ \\
\hline Centrifuging sour pomegranate seeds & $9.78 \pm 0.82^{\mathrm{c}, \mathrm{A}}$ & $9.48 \pm 1.00^{\mathrm{d}, \mathrm{A}}$ & $9.15 \pm 1.09^{\mathrm{d}, \mathrm{A}}$ & $8.64 \pm 1.14^{\mathrm{d}, \mathrm{A}, \mathrm{B}}$ & $8.32 \pm 1.13^{\mathrm{d}, \mathrm{A}, \mathrm{B}}$ & $7.19 \pm 0.87^{\mathrm{bB}}$ \\
\hline \multicolumn{7}{|l|}{ Acid treatment } \\
\hline Squeezing sweet pomegranate fruit & $0.56 \pm 0.02^{\mathrm{a}, \mathrm{B}}$ & $0.76 \pm 0.11^{\mathrm{a}, \mathrm{A}}$ & $0.75 \pm 0.14^{\mathrm{a}, \mathrm{A}}$ & $0.71 \pm 0.00^{\mathrm{a}, \mathrm{A}}$ & $0.70 \pm 0.01^{\mathrm{a}, \mathrm{A}}$ & $0.68 \pm 0.01^{\mathrm{a}, \mathrm{A}}$ \\
\hline Centrifuging sweet pomegranate seeds & $0.34 \pm 0.06^{\mathrm{c}, \mathrm{B}}$ & $0.50 \pm 0.00^{b, A}$ & $0.54 \pm 0.25^{b, A}$ & $0.53 \pm 0.00^{b, A}$ & $0.54 \pm 0.03^{\mathrm{b}, \mathrm{A}}$ & $0.51 \pm 0.05^{\mathrm{b}, \mathrm{A}}$ \\
\hline Squeezing sour pomegranate fruit & $0.47 \pm 0.00^{b, A}$ & $0.46 \pm 0.12^{b, A}$ & $0.45 \pm 0.00^{\mathrm{b}, \mathrm{A}}$ & $0.43 \pm 0.00^{c, A}$ & $0.43 \pm 0.00^{c, A}$ & $0.42 \pm 0.01^{\mathrm{c}, \mathrm{A}}$ \\
\hline Centrifuging sour pomegranate seeds & $0.30 \pm 0.00^{c, A}$ & $0.30 \pm 0.05^{\mathrm{c}, \mathrm{A}}$ & $0.29 \pm 0.02^{c, A}$ & $0.28 \pm 0.01^{\mathrm{d}, \mathrm{A}, \mathrm{B}}$ & $0.27 \pm 0.01^{\mathrm{d}, \mathrm{B}}$ & $0.26 \pm 0.01^{\mathrm{d}, \mathrm{B}}$ \\
\hline
\end{tabular}

Means \pm SD of 10 samples followed by different superscript letters are significantly different at $p<0.05$. The small letters indicate differences in the treatments (columns), while the capital letters indicate differences in the storage time (rows).

at the beginning of storage ( $5 \mathrm{~h}$ and $15 \mathrm{~h}$ ) could be due to the de novo synthesis of anthocyanin from carbohydrates (Aarabi et al., 2008) whereas decrease in its concentration with increase in storage time could be likely due to chemical reactions and microbial metabolism. Previous studies have also demonstrated the varying levels of anthocyanin in pomegranate juice of different origins such as Tunisian (Hasnaoui et al., 2011), Iranian (Alighourchi et al., 2008) and Turkey (Türkyılmaz, 2013) varieties. These studies established the influence of genotypes, environmental conditions, maturity stage, post-harvest processing and juice extraction processes on the levels of anthocyanin found in pomegranate juice. In addition, similar changing trend during storage of pomegranate juice extracted by two processes (squeezing and centrifugation) was also reported by Aarabi et al. (2008).

\section{Sensory attributes of pomegranate juice}

The sensory attributes of pomegranate juice prepared from two local varieties (sweet and sour) using two 
Table 5. Sensory attributes of local sweet (Taif) and sour (Bidah) pomegranate juice produced by two different methods and from two different types of local verities.

\begin{tabular}{lllllll} 
& \multicolumn{4}{c}{ Sensory attributes } \\
\cline { 2 - 7 } Treatments & Stability & Color & Flavor & Texture & Smell & $\begin{array}{l}\text { Overall } \\
\text { acceptance }\end{array}$ \\
\hline Squeezing sweet pomegranate fruit & $17.7 \pm 2.78^{\mathrm{a}}$ & $17.5 \pm 2.2^{\mathrm{a}}$ & $17.76 \pm 2.82^{\mathrm{a}}$ & $17.00 \pm 3.83^{\mathrm{a}}$ & $17.66 \pm 3.06^{\mathrm{a}}$ & $17.96 \pm 2.39^{\mathrm{a}}$ \\
Centrifuging sweet pomegranate seeds & $15.93 \pm 3.03^{\mathrm{ab}}$ & $15.76 \pm 3.6^{\mathrm{ab}}$ & $16.70 \pm 3.14^{\mathrm{ab}}$ & $14.93 \pm 4.20^{\mathrm{ab}}$ & $16.86 \pm 3.54^{\mathrm{a}}$ & $16.26 \pm 2.80^{\mathrm{a}}$ \\
Squeezing sour pomegranate fruit & $15.16 \pm 3.75^{\mathrm{b}}$ & $14.36 \pm 4.24^{\mathrm{b}}$ & $15.20 \pm 4.12^{\mathrm{ab}}$ & $13.70 \pm 5.03^{\mathrm{ab}}$ & $16.63 \pm 2.97^{\mathrm{a}}$ & $15.26 \pm 2.91^{\mathrm{a}}$ \\
Centrifuging sour pomegranate seeds & $13.50 \pm 4.99^{\mathrm{ab}}$ & $14.53 \pm 5.42^{\mathrm{ab}}$ & $14.13 \pm 5.09^{\mathrm{b}}$ & $13.16 \pm 5.65^{\mathrm{b}}$ & $16.36 \pm 3.66^{\mathrm{a}}$ & $14.20 \pm 4.72^{\mathrm{a}}$ \\
\hline
\end{tabular}

Means \pm SD of 10 samples followed by different superscript letters are significantly different at $p<0.05$.

extraction processes are shown in Table 5. Generally, the juice prepared from sweet fruits outscores the one prepared from sour fruits in all sensory attributes. This is due to the above-mentioned results, which indicated the superiority of sweet pomegranate juice over sour variety considering the levels of chemical components, namely sugars, organic acids and anthocyanins. Similarly, it has been reported that the juice prepared from sweet pomegranate fruits received higher preferences than that prepared from sweet-sour and sour fruits (MayuoniKirshinbaum et al., 2013). The scores of overall acceptability and all sensory attributes of all juice types were higher than 13, suggesting that the panelists ranked all juice types as very good and excellent, with the highest preference to the juice prepared from whole sweet fruits and the least preference for the juice prepared from the seeds of peeled off fruits. Previous studies have demonstrated that the sensory attributes of pomegranate juice depended on the factors such as genotype, maturity, season, agronomical practices, climatic conditions and processing methods (Borochov-Neori et al., 2009; Mayuoni-Kirshinbaum et al., 2013; Vázquez-Araújo et al., 2014). Overall, the produced juices could have high consumer acceptability regardless of the fruit type and the extraction process.

\section{Conclusion}

This study investigated the production of pomegranate juice from local varieties using two different extraction processes (squeezing whole fruit, and centrifuging fruit seeds after removal of fruit peels). The results established that the quality attributes of the produced juice were affected by genotype, extraction method and storage period at different magnitudes. The juice prepared from the sweet variety had higher $\mathrm{pH}$ and sensory acceptability, and lower acidity and anthocyanin level than the juice prepared from sour fruits. Concerning the processing methods, the juice prepared by squeezing the whole fruit outscore, in most of quality attributes, the juice prepared by centrifuging the seeds after removal of fruit peels. Storage duration affected the quality attributes in a fluctuated manner. Overall, squeezing unpeeled pomegranate fruit is the most economical and easy process to produce acceptable and stable juice, especially from sweet pomegranate fruits. The future studies must specifically address the effect of sterilization and long storage conditions on the quality attributes of pomegranate juice.

\section{Acknowledgments}

This research was funded by Princess Nourah bint Abdulrahman University Researchers Supporting Project Number PNURSP2022R249, Princess Nourah bint Abdulrahman University, Riyadh, Saudi Arabia.

\section{References}

Aarabi A., Barzegar M., and Azizi M.H. 2008. Effect of cultivar and cold storage of pomegranate (Punica granatum L.) juices on organic acid composition. ASEAN Food J. 15(15): 45-55.

Akhtar S., Ismail T., Fraternale D., and Sestili P. 2015. Pomegranate peel and peel extracts: chemistry and food features. Food Chem. 174: 417-425. https://doi.org/10.1016/j. foodchem.2014.11.035

Akyıldız A., Karaca E., Ağçam E., Dündar B., and Çınkır N.I. 2020. Changes in quality attributes during production steps and frozenstorage of pomegranate juice concentrate. J Food Compos Anal. 92: 103548. https://doi.org/10.1016/j.jfca.2020.103548

Alighourchi H., Barzegar M., and Abbasi S. 2008. Anthocyanins characterization of 15 Iranian pomegranate (Punica granatum L.) varieties and their variation after cold storage and pasteurization. Eur Food Res Technol. 227: 881-887. https://doi. org/10.1007/s00217-007-0799-1

Association of Official Analytical Chemists (AOAC). 2000. Official methods of analysis. 17th ed. AOAC, Gaithersburg, MD.

Borochov-Neori H., Judeinstein S., Tripler E., Harari M., Greenberg A., Shomer I., and Holland D. 2009. Seasonal and cultivar variations in antioxidant and sensory quality of pomegranate (Punica granatum L.) fruit. J Food Compos Anal. 22: 189-195. https://doi.org/10.1016/j.jfca.2008.10.011 
Chen J., Serafin F.L., Pandya R.N., and Daun H. 1991. Effects of extrusion conditions on sensory properties of corn meal extrudates. J Food Sci. 56: 84-89. https://doi.org/10.1111/j.1365-2621.1991. tb07981.x

Coronado-Reyes J.A., Cortés-Penagos C.D.J., and GonzálezHernández J.C. 2021. Chemical composition and great applications to the fruit of the pomegranate (Punica granatum): a review. Food Sci Technol. 2021: 1-8. https://doi.org/10.1590/fst.29420

Fadavi A., Barzegar M., Azizi M.H., and Bayat M. 2005. Note. Physicochemical composition of ten pomegranate cultivars (Punica granatum L.) grown in Iran. Food Sci Technol Int. 11: 113-119. https://doi.org/10.1177/1082013205052765

Fahmy H., Hegazi N., El-Shamy S., and Farag M.A. 2020. Pomegranate juice as a functional food: a comprehensive review of its polyphenols, therapeutic merits, and recent patents. Food Funct. 11: 5768-5781. https://doi.org/10.1039/d0fo01251c

Ghaderi-Ghahfarokhi M., Barzegar M., and Nabil M. 2016. Geographical discrimination of Iranian pomegranate cultivars based on organic acids composition and multivariate analysis. J Agr Sci Tech. 18: 1221-1232. http://hdl.handle. net/123456789/3788

Gundogdu M. and Yilmaz H. 2012. Organic acid, phenolic profile and antioxidant capacities of pomegranate (Punica granatum L.) cultivars and selected genotypes. Sci Hortic. 143 38-42. https:// doi.org/10.1016/j.scienta.2012.05.029

Hasnaoui N., Jbir R., Mars M., Trifi M., Kamal-Eldin A., Melgarejo P., and Hernandez F. 2011. Organic acids, sugars, and anthocyanins contents in juices of Tunisian pomegranate fruits. Int J Food Prop. 14: 741-757. https://doi. org/10.1080/10942910903383438

Hegazi N.M., El-Shamy S., Fahmy H., and Farag M.A. 2021. Pomegranate juice as a super-food: a comprehensive review of its extraction, analysis, and quality assessment approaches. J Food Compos. Anal. 97: 103773. https://doi.org/doi: 10.1016/j. jfca.2020.103773

Ikegaya A., Toyoizumi T., Ohba S., Nakajima T., Kawata T., Ito S., and Arai E. 2019. Effects of distribution of sugars and organic acids on the taste of strawberries. Food Sci. Nutr. 7: 2419-2426. https://doi.org/10.1002/fsn3.1109

Ismail T., Sestili P., and Akhtar S. 2012. Pomegranate peel and fruit extracts: a review of potential anti-inflammatory and anti-infective effects. J Ethnopharmacol. 143: 397-405. https://doi. org/10.1016/j.jep.2012.07.004

Kostka T., Ostberg-PotthoffJ.J., Briviba K., Matsugo S., Winterhalter P., and Esatbeyoglu T. 2020. Pomegranate (Punica granatum L.) extract and Its anthocyanin and copigment fractions-free radical scavenging activity and influence on cellular oxidative stress. Foods. 9: 1617. https://doi.org/10.3390/foods9111617

Mayuoni-Kirshenbaum L., Bar-Ya'akov I., Hatib K., Holland D., and Porat, R. 2013. Genetic diversity and sensory preference in pomegranate fruits. Fruits. 68: 517-524. https://doi. org/10.1051/fruits/2013090

Mena P., Martí N., and García-Viguera C. 2014. Chapter 18 - The impact of processing and storage on the (poly)phenolic fraction of pomegranate (Punica granatum L.) juices. In Processing and impact on antioxidants in beverages, Editor(s): Victor Preedy. Academic Press, San Diego, pp. 173-184.

Miguel G., Dandlen S., Antunes D., Neves A., and Martins D. 2004. The effect of two methods of pomegranate (Punica granatum $\mathrm{L}$ ) juice extraction on quality during storage at $4{ }^{\circ} \mathrm{C}$. J Biomed Biotechnol. 2004: 332-337. https://doi.org/10.1155/ S1110724304403064

Mphahlele R.R., Fawole O.A., Mokwena L.M., and Opara U.L. 2016. Effect of extraction method on chemical, volatile composition and antioxidant properties of pomegranate juice. S Afr J Bot. 103: 135-144. https://doi.org/10.1016/j.sajb.2015.09.015

Mphahlele R.R., Fawole O.A., Stander M.A., and Opara, U.L. 2014. Preharvest and post-harvest factors influencing bioactive compounds in pomegranate (Punica granatum L.)-a review. Sci Hortic. 178: 114-123. https://doi.org/10.1016/j. scienta.2014.08.010

Roscoe J.T. 1975. Fundamental research statistics for the behavioral sciences. Holt, Rinehart and Winston, New York, NY.

Topalović A., Knežević M., Gačnik S., and Mikulic-Petkovsek M. 2020. Detailed chemical composition of juice from autochthonous pomegranate genotypes (Punica granatum L.) grown in different locations in Montenegro. Food Chem. 330: 127261. https://doi.org/10.1016/j.foodchem.2020.127261

Topalović A., Knežević M., Ivanović L., Gačnik S., and MikulicPetkovsek M. 2021. Phytochemical screening of wild pomegranate (Punica granatum L.) juices from the market. J. Food Compost. Anal. 100: 103933. https://doi.org/10.1016/j.jfca.2021.103933

Türkyılmaz M. 2013. Anthocyanin and organic acid profiles of pomegranate (Punica granatum L.) juices from registered varieties in Turkey. Int J Food Sci Technol. 48: 2086-2095. https:// doi.org/10.1111/ijfs.12190

Vázquez-Araújo L., Nuncio-Jáuregui P.N., Cherdchu P., Hernández F., Chambers IV, E, and Carbonell-Barrachina Á.A. 2014. Physicochemical and descriptive sensory characterization of Spanish pomegranates: aptitudes for processing and fresh consumption. Int J Food Sci Technol. 49: 1663-1672. https://doi. org/10.1111/ijfs.12472 